\title{
MUSCLE DISORDERS
}

CONGENITAL INFLAMMATORY MYOPATIY

Three patients with congenital inflammatory myopathy are reported from the Montreal Children's Hospital and Neurological Institute McGill University, Montreal, Canada. Seven additional cases are reviewed from the literature. The essential criteria for diagnosis were 1) antenatal or neonatal presentation with decreased fetal movements, muscular hypotonia and weakness with or without arthrogryposis, and 2) muscle biopsy evidence for inflamatory cell infiltrate and muscle fiber damage. CPK is elevated and the EMG is myopathic. CNS involvement was present in six of the patients. Two died, one at nine months and the other at five years. Treatment with steroids was used in 7 of the 10 patients with variable results. Possible etiologies included intrauterine viral infection or an autoimmune process. (Shevell M et al. Congenital inflanmatory myopathy.

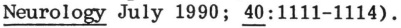

COMNENT: Congenital inflammatory myopathy is a rare cause of the "floppy infant syndrome", and the differential diagnosis includes a congenital muscular dystrophy syndrome of Fukuyama or Walker-Warburg. Fukuyama's congenital muscular dystrophy includes hydrocephalus, ocular manifestations and mental retardation and Walker-Warburg's syndrome is characterized by lissencephaly and retinal abnormalities. Treatment of the cases of congenital inflammatory myopathy with steroids may improve motor development but does not result in intellectual improvement.

\section{EARLY DEVELOPMENT IN DUCHENNE MUSCULAR DYSTROPHY}

The early development of 33 boys wi th Duchenne muscular dystrophy

(IMD) was assessed at the Institute of Miedical Genetics, University of Wales College of Medicine, Heath Park, Cardiff, Wales. The average age of entry into the study was 3.4 years (range 0.8 to 6.7 ). The Griffiths Developmental Scales, The Reynell Language Scales and the British Picture Vocabulary Scales were used at three evaluations at 6 monthly intervals over a one year period. Compared to a control group the boys with DMD showed developmental delay which was most severe in the locomotor and language areas. Locomotor quotients deteriorated over time and behavior problems were probably secondary to the developmental delay. (Smith RA et al Early development of boys with Duchenne muscular dystrophy. Dev Med Child Neurol June 1990; 32:519-527).

COMNENT: Unexplained developmental delays should prompt a neurological evaluation to exclude Duchenne muscular dystrophy in boys. Young children wi th $\mathrm{DMD}$ have significant problems with motor, speech and behavioral disorders before muscle weakness becomes an obvious clinical sign.

The etiology of intellectual impairment in Duchenne muscular dystrophy was investigated by MRI studies at Jordan University, 